\title{
PAPER
}

Cite this: Analyst, 2013, 138, 3444

\section{Comparative local analysis of metabolites, lipids and proteins in intact fish tissues by LAESI mass spectrometry $\dagger$}

\author{
Bindesh Shrestha, ${ }^{a}$ Robert Javonillo, $t^{\mathrm{b}}$ John R. Burns, ${ }^{\mathrm{b}}$ Zsolt Pirger $^{\mathrm{c}}$ and Akos Vertes ${ }^{* a}$ \\ Direct mass spectrometric analysis of animal tissues is an emerging field enabled by recent developments in \\ ambient ion sources. Label-free in situ analysis of metabolites, lipids, and peptides/proteins from intact \\ tissues in whole fish specimens of different gender and age were performed by laser ablation \\ electrospray ionization (LAESI) mass spectrometry (MS). Hypertrophied glandular tissue (gill gland) of \\ adult male Aphyocharax anisitsi (bloodfin tetra) was compared with gill tissues in females of the same \\ species. Comparison of a large number of sample-specific ions was aided by a multivariate statistical \\ method based on orthogonal projections to latent structures discriminant analysis. More than 200 \\ different ions were detected in the mass spectra corresponding to primary metabolites, hormones, lipids \\ and peptides/proteins. The gill tissues of the sexually mature males exhibited multiply charged ions in \\ the $6+$ to $10+$ charge states corresponding to a protein with a molecular weight of $11380 \mathrm{Da}$. This \\ protein was present only in the mature male gill glands but absent in the corresponding area of the \\ female and immature male specimens. An additional nine proteins were detected by LAESI-MS in both \\ the male and female gill tissues.
}

Received 31st March 2013 Accepted 27th April 2013

DOI: 10.1039/c3an00631j

www.rsc.org/analyst methods were primarily utilized for analysing metabolites and lipids. ${ }^{15-18}$ Protein analysis from dried biological samples such as blood, cell cultures, and tissues was demonstrated by electrospray assisted laser desorption ionization (ELDI) MS. ${ }^{19}$ In extracts and crude samples, desorption electrospray ionization (DESI) provided peptide and protein analysis including top down sequencing. ${ }^{20-22}$ Sensitive analysis of proteins was performed by extractive electrospray ionization mass spectrometry (EESI) by infusing untreated biological samples into the electrospray plume. ${ }^{23}$

Laser ablation electrospray ionization (LAESI) MS is an ambient ionization technique that employs mid-infrared (mid-IR) laser pulses to locally ablate the tissue or cell sample and electrospray for the ionization of the ejected material. ${ }^{24}$ The strong absorption maximum of water at $2.94 \mu \mathrm{m}$ wavelength enables the deposition of laser energy into water-rich tissues, for example, the unmodified gill filaments and gill glands of fish, for microsampling. Similar mid-IR laser-based ambient ionization techniques such as atmospheric pressure (AP) MALDI, IR laserassisted desorption electrospray ionization (IR-LADESI), matrixassisted laser desorption electrospray ionization (MALDESI), and IR-ELDI were also explored for the analysis of proteins. ${ }^{25-29}$ Metabolites and lipids in various tissues, including rodent brains and the untreated electric organ of the torpedo fish (Torpedo californica), were analysed by LAESI-MS. ${ }^{18,30-32}$

Fish gills have diverse biological functions, such as aquatic gas exchange, osmotic regulation, and waste excretion. ${ }^{33}$ Mature males of certain fishes in the family Characidae, order 
Characiformes, form a glandular structure, the so called gill gland, in the anterior gill cavities. ${ }^{34,35}$ Both light and transmission electron microscopy demonstrated the presence of secretory vesicles in the columnar cells lining the gill gland. On occasion, periodic acid-Schiff stained (PAS+) material was observed within the lumina of the gill gland chambers (see the PAS+ stained regions in Fig. 2) $\cdot^{34-36}$ Due to the secretory nature of gill glands and their development as male secondary sex characters, it was hypothesized that these structures might release some type of male sexual chemical signal or pheromone. ${ }^{36,37}$

During development of gill glands, the secondary lamellae of the gill filaments involved shorten or even atrophy completely, while tall columnar cells populate the areas between adjacent secondary lamellae. In addition, the tips of adjacent gill filaments fuse and an epithelial "cover" grows over the lateral regions of adjacent gill filaments such that enclosed chambers are formed with openings into the main gill cavity only at the ventral extremities of these chambers. ${ }^{36}$ In Aphyocharax anisitsi (bloodfin tetra), a typical gill gland is formed by the fusion of $\sim 5$ gill filaments producing a structure that is $200-300 \mu \mathrm{m}$ wide and $\sim 700 \mu \mathrm{m}$ long. Due to the small volume of the gill gland chambers, biochemical analysis of their contents has not been performed.

In this contribution, we present in situ comparative molecular analysis of exposed gill tissue in males and females of $A$. anisitsi. LAESI-MS is used for the simultaneous analysis of small metabolites, lipids and some peptides/proteins. Further analysis of the data by a multivariate statistical tool, orthogonal projections to latent structures discriminant analysis (OPLS-DA), is shown to be helpful in finding differences between the biochemical profiles of the compared samples. Direct LAESI-MS enables the in situ analysis of tissue exposed from the whole animal without sample preparation, e.g., histological sectioning, drying or matrix coating.

\section{Experimental}

\section{Fish specimens}

A. anisitsi (bloodfin tetra) were obtained from a local pet store in Arlington, VA, USA. All fish specimens included in this study had standard lengths (SL) between 31.0 and $38.0 \mathrm{~mm}$. Each specimen was euthanized by immersion in buffered tricaine methanesulfonate (MS-222) at $300 \mathrm{mg} \mathrm{L}^{-1}$ for 10 minutes after cessation of opercular movements. One operculum was immediately removed and either the gill gland or the adjacent unmodified gill tissue (if a male) or the anterior-most gill filaments on the first gill arch (if a female) was laser ablated and analysed. The entire fish was placed on a glass slide for the LAESI-MS analysis within few minutes of euthanization (see inset in Fig. 1). The euthanized fish was then fixed in $10 \%$ formalin under a fume hood for later histological studies of the gill tissues.

For the periodic acid-Schiff (PAS) reagent histochemical study, sexually mature adult male of another species of characid fish, Othonocheirodus sp., SL $37.8 \mathrm{~mm}$, was obtained from the collection of the Field Museum of Natural History in Chicago (voucher number FMNH 99496).

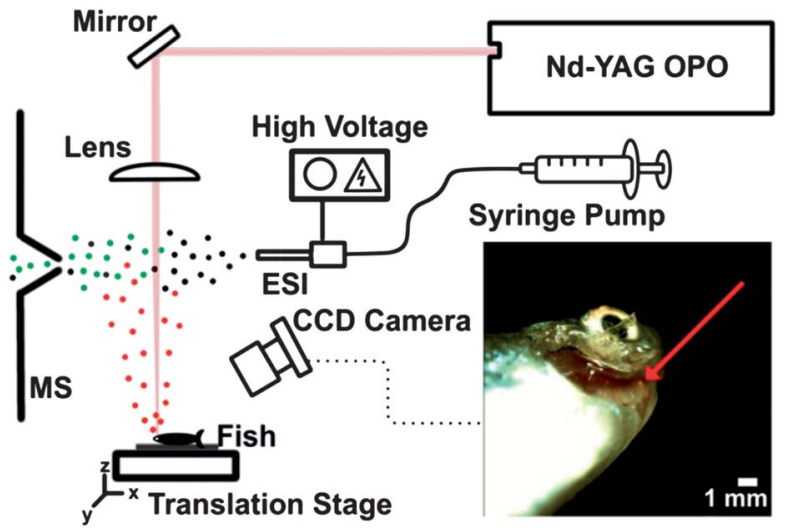

Fig. 1 Schematic of LAESI-MS analysis of gill glands in A. anisitsi. Mid-IR laser beam was aimed at the point of interest within the exposed tissue. Aiming was achieved by collinear a HeNe laser beam and a CCD observation camera. The inset shows the image captured by the CCD camera of a male A. anisitsi with the exposed gill gland prior to the LAESI-MS analysis. The arrow shows the spot painted by the aiming HeNe laser on the exposed gill gland.

All animal procedures and experiments fully complied with the principles set forth in the "Guide for the Care and Use of Laboratory Animals" prepared by the Committee on Care and Use of Laboratory Animals of the Institute of Laboratory Resources, National Research Council, and were approved by the George Washington University Institutional Animal Use and Care Committee.

\section{Chemicals}

HPLC grade water and methanol were purchased from Acros Organics (Geel, Belgium), and glacial acetic acid was obtained from Fluka (Munich, Germany). All the chemicals were used without further purification.

\section{LAESI-MS}

The schematic of the LAESI-MS setup, depicted in Fig. 1, is similar to the systems described earlier. ${ }^{\mathbf{1 8 , 2 4}}$ Laser ablation was performed using a Nd:YAG laser-driven optical parametric oscillator (Opolette, Opotek, CA, USA) running at $2.94 \mu \mathrm{m}$ wavelength and $20 \mathrm{~Hz}$ repetition rate with $5 \mathrm{~ns}$ pulse width.

Using the built-in aiming HeNe laser, the laser beam was aligned by gold-coated mirrors (PF10-03-M01, Thorlabs, Newton, NJ) and focused by a $15 \mathrm{~mm}$ focal length plano-convex calcium fluoride lens (Infrared Optical Products, NY).

The euthanized fish specimen was placed on a glass microscope slide attached to a 3-axis translation stage in order to manoeuvre the sample with respect to the laser beam. The aiming of the laser beam on the sample was visualized by a home built imaging system consisting of a CCD camera (Marlin F131, Allied Vision Technologies, Stadtroda, Germany) fitted with a macro lens $(50 \mathrm{~mm} \mathrm{f} / 3.5 \mathrm{MD}$ macro manual focus lens, Konica Minolta, Tokyo, Japan). This helped with the accurate targeting of the gill tissue by the mid-IR laser beam.

A home-built electrospray setup made with a tapered stainless steel emitter (i.d. $50 \mu \mathrm{m}$, MT320-50-5-5, New Objective, 
Woburn, MA, USA) was used to spray $50 \%$ methanol with $0.1 \%$ (v/v) acetic acid solution supplied at $300 \mathrm{~nL} \mathrm{~min}^{-1}$ flow rate by a syringe pump (Physio 22, Harvard Apparatus, Holliston, MA, USA). Stable high voltage was delivered by a regulated power supply (PS350, Stanford Research Systems, Sunnyvale, CA, USA). In LAESI, the neutrals produced by mid-IR laser ablation were ionized by an electrospray. The ions produced by LAESI were detected by an orthogonal acceleration time-of-flight mass spectrometer (Q-TOF Premier, Waters Co., Milford, MA, USA). All the spectra were recorded in positive ion mode with resolution of 8000 based on full width at half-maximum.

\section{Histotechniques}

After fixation for one week in $10 \%$ formalin, the following tissues were analyzed histologically: in males, gill glands and adjacent tissue from the side of the head opposite to the ablation; in females, first gill arches from the side of the head opposite to the ablated tissue. Gill tissues were initially decalcified in acid alcohol. All tissues were then dehydrated in an ethanol series to $95 \%$, infiltrated and embedded in glycol methacrylate, sectioned at $3.5 \mu \mathrm{m}$ using glass knives on a Sorvall Type JB-4 microtome, and stained with toluidine blue or the PAS reagent technique.

\section{Data analysis}

The mass spectra were acquired and analyzed using MassLynx version 4.1 (Waters Co., Milford, MA, USA). Background electrospray peaks were subtracted in MassLynx to obtain LAESI mass spectra of sample-related ions. Locking the mass scale of LAESI mass spectra to an internal standard provided high mass accuracy. Deconvolution of the multiply charged ion peaks in the higher $\mathrm{m} / \mathrm{z}$ range was performed using MaxEnt 1 software, based on a maximum entropy deconvolution method, within MassLynx. ${ }^{38}$ Further confirmation of proper deconvolution was obtained by MagTran 1.02 software that uses the ZScore algorithm..$^{39}$ Multivariate statistical analysis of mass spectra based on OPLS-DA was performed by the MarkerLynx software (Waters Co., Milford, MA, USA).

\section{Results and discussion}

\section{Histochemical analysis}

Histochemical analysis on gill glands from fishes of the family Characidae has demonstrated the presence of material stainable by PAS reagent technique within the gill gland chambers. ${ }^{35,36}$ Sagittal section through the first gill arch of sexually mature adult male Othonocheirodus sp., another species of characid fish, shows the gill gland and more posterior unmodified gill filaments (see Fig. 2). Positive staining by PAS reagent (PAS+) implies the presence of macromolecules with carbohydrate moiety, such as glycogen, glycoprotein or proteoglycans. ${ }^{40}$

Abundant PAS+ secretion is present within the chambers of the gill gland, which is presumably released into the main gill cavity through the openings at the ventral extremity of each gill gland chamber.

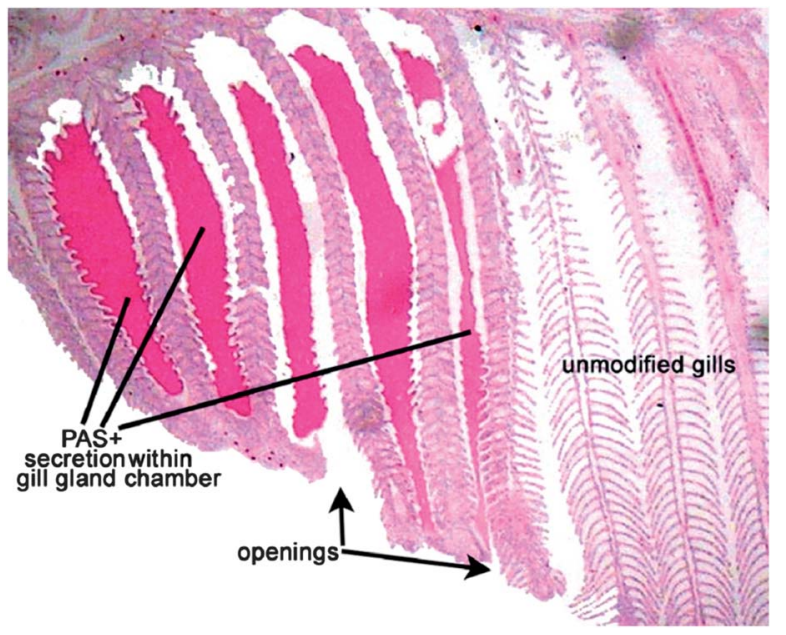

Fig. 2 Sagittal section through first gill arch of sexually mature adult male species of characid fish, shows PAS+ secretion within the chambers in the gill gland and the lack of staining (PAS-) in posterior unmodified gill filaments. Anterior is to the left.

\section{Direct analysis by LAESI-MS}

LAESI mass spectra were collected from the exposed gill glands of the adult male specimens, from the tissue adjacent to the gill glands, and from the location corresponding to the gill glands in female specimens of A. anisitsi. A typical positive ion LAESI mass spectrum from the gill gland of an adult male is shown in Fig. 3. A single LAESI mass spectrum contains numerous different ions corresponding to metabolites, lipids and peptides/proteins.

A preliminary assessment of the LAESI mass spectra indicated the presence of more than 200 positive ionic species in each analysis. Over 120 small metabolite related peaks were found in the $\mathrm{m} / \mathrm{z}<600$ range, $\sim 30$ lipid-related species were found in the $600<m / z<900$ range, and $\sim 50$ multiply charged peptide and protein peaks fell in the $1000<m / z<2200$ range. The structural

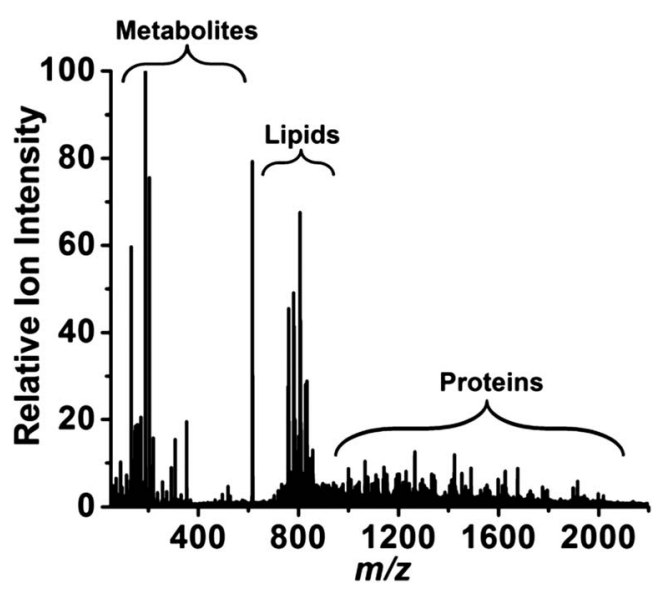

Fig. 3 LAESI mass spectrum from the gill glands of the adult male $A$. anisitsi contains approximately two hundred different ions corresponding to metabolites, lipids and peptides/proteins. 
identity of approximately $10 \%$ of these ions was determined by their tandem mass spectra. Examples of the assigned small metabolites include choline, creatine, acetylcholine, histidine, essential amino acids, monosaccharides, thiamine or panthotenic acid (vitamin B5). We also identified coenzyme-A in the gill gland that can be synthesised from panthotenic acid, and is involved in the synthesis of amino acids, phospholipids, fatty acids, ketones, steroid hormones, neurotransmitters (such as acetylcholine) and cholesterol. For example, cholesterol is a precursor to the synthesis of steroids (progesterone, estrogens, androgens, mineralocorticoids and glucocorticoids). The $600<$ $m / z<900$ range exhibits over 30 lipid peaks dominated by glycerophospholipids, such as phosphatidylcholines [PC(34:2), $\mathrm{PC}(34: 1), \mathrm{PC}(36: 4), \mathrm{PC}(36: 2), \mathrm{PC}(36: 1)$, etc. $]$. Table S1 in the ESI $\dagger$ lists the metabolite and lipid molecules tentatively identified in the gill glands of male fishes by LAESI-MS.

\section{Multivariate statistical data analysis}

Comparing the large number of ions detected in different sample types can result in complex and time consuming data analysis. In comparative studies, the OPLS model can be used to extract the differences between LAESI spectra. ${ }^{32}$ In OPLS-DA, the differences between the mass spectra of the two sexes are expressed in the correlated variation of the first predictive component $\left(t_{\mathrm{p}}\right)$ and uncorrelated variation in the orthogonal component $\left(t_{\mathrm{o}}\right)$. The covariance and correlation loading profiles based on the predictive component $\left(t_{\mathrm{p}}\right)$ can be visualized by a scatter plot, or S-plot, as shown in Fig. 4. As indicated by the labels in the S-plot, positive correlation corresponds to ion peaks from the gill tissue of female specimens and the negative axis denotes male specimens. High negative scores for covariance and correlation select for the ions that are most specific to

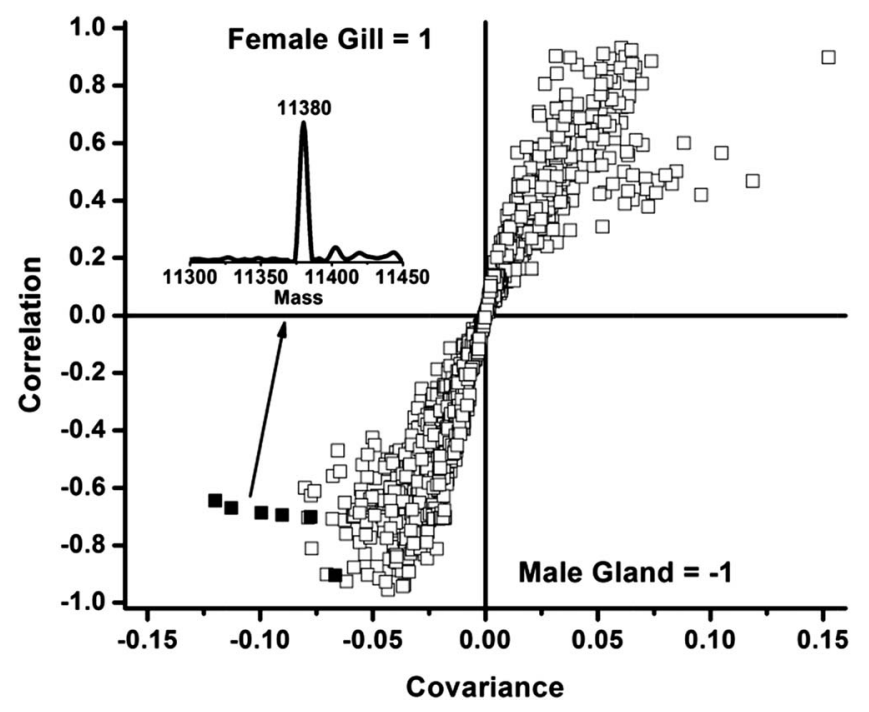

Fig. 4 OPLS-DA model based S-plot selects the ions that produce the most variance in the metabolite, lipid and protein peaks between the LAESI mass spectra of mature male and female $A$. anisitsi gill tissues. The arrow indicates the ion associated with a protein peak at $11380 \mathrm{Da}$ that is exclusively found in gill glands of mature males. The inset shows the deconvoluted spectrum with a peak at neutral mass $11380 \mathrm{Da}$.

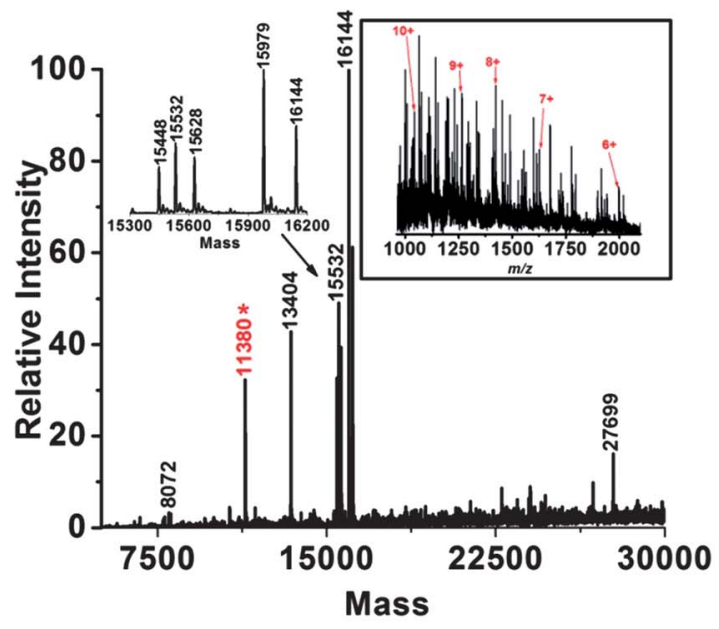

(a)

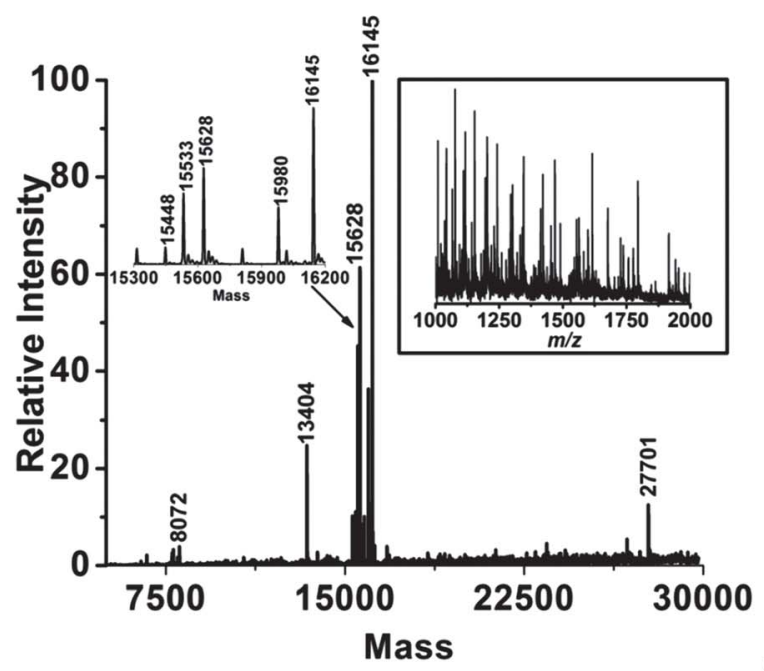

(b)

Fig. 5 Deconvoluting (MaxEnt) the high-mass section of LAESI mass spectra of A. anisitsi revealed the presence of nine peptides and proteins in the (a) male gill gland and (b) female gill tissue. Some multiply charged peaks, denoted by arrows in the framed inset of panel (a), were found exclusively in the sexually mature male gill tissue. They corresponded to a protein with a molecular weight of 11380 Da (asterisk).

male gill tissues. Ions with low absolute values of covariance and correlation are present in both male and female gill spectra. To explore the identity of biomolecules that are specific to the gills of mature male $A$. anisitsi, a relatively small number of ions with large negative covariance and correlation need to be analyzed. The solid squares in Fig. 4 belong to multiply charged ions specific to a protein with $11380 \mathrm{Da}$ neutral mass in the gill glands of male fish.

\section{In situ protein detection}

Most ambient ionization techniques exhibit relative sensitivities that favour a particular group of compounds. This phenomenon is usually attributed to ion suppression effects. Although such effects also exist in LAESI, the spectra produced by LAESI-MS from these tissues indicate simultaneous detection of small metabolites, lipids and some proteins. 
To deconvolute the multiply charged peaks in the LAESI mass spectra of $A$. anisitsi between $\mathrm{m} / \mathrm{z} 1000$ and 2200, two software packages based on the MaxEnt and ZScores algorithms were utilized. Two examples of deconvoluted spectra are presented in Fig. 5. Both algorithms showed deconvoluted spectral features corresponding to eleven proteins with neutral masses of 8072, 13 404, 15 313, 15 448, 15 532, 15 554, 15 628, 15 669, 15 979, 16144 and $27699 \mathrm{Da}$ for all gill tissues.

In addition, the mass spectra of the gill glands in the sexually mature male showed the presence of multiply charged ions in the +6 to +10 charge states corresponding to a protein with a molecular weight of $11386 \mathrm{Da}$. This protein was present in the male gill glands but absent in the adjacent areas of the male specimen and in the corresponding area of the female specimen. The localization of this protein shows an interesting correlation with the PAS+ glycoprotein detected in fishes of the same family (see Fig. 2).

The unique protein found only in the mature male gill glands using rapid screening by LAESI-MS can be related to the function of this modified organ. Further work based on conventional proteomics will be required to fully characterize this protein. The deconvoluted spectra of male gill tissue and corresponding female tissues are presented in Fig. $5 a$ and b, respectively. The portion of LAESI mass spectra between $\mathrm{m} / \mathrm{z} 1000$ and 2200 from gill gland of adult male $A$. anisitsi and gill tissue of female is shown as insets in Fig. 5a and b, respectively. The unique protein found in the male tissue and corresponding multiply charged peaks (in inset) in mass spectra is highlighted by an asterisk in Fig. 5a. Although the function of this protein at $11380 \mathrm{Da}$ is unknown, it may represent the chemical signal, or perhaps a regulatory protein or enzyme involved in the production of the chemical species responsible for such a signal.

\section{Conclusions}

Microscale analysis for the in situ detection of small metabolites, lipids and peptides/proteins from fish tissues was demonstrated by LAESI-MS. The diversity of molecular classes detected in LAESI spectra demonstrates that it has the potential for the simultaneous detection of small metabolites, lipids and proteins directly from the sample. Comparative analysis of gill tissues from fishes of different gender and ages indicated that mature males had a unique protein in their gill glands. The discovery of this 11380 Da protein using rapid screening by the LAESI technique will have to be followed by further work based on established proteomics methods, including de novo sequencing and/or peptide mapping. Further improvement in the sensitivity achieved for proteins can be attained by optimizing the electrospray solvent and enhancing the interaction of the laser ablation and electrospray plumes. The results obtained by local LAESI-MS analysis in conjunction with multivariate statistical data processing show that this approach can be utilized for rapid exploration of biomarker candidates.

\section{Acknowledgements}

The authors acknowledge the financial support from the Division of Chemical Sciences, Geosciences, and Biosciences, Office of Basic Energy Sciences of the U.S. Department of Energy (DEFG02-01ER15129), and the George Washington University Selective Excellence Fund.

\section{Notes and references}

1 M. R. Viant, Mol. BioSyst., 2008, 4, 980-986.

2 X. J. Feng, X. Liu, Q. M. Luo and B. F. Liu, Mass Spectrom. Rev., 2008, 27, 635-660.

3 J. J. Lohne, W. C. Andersen, S. B. Clark, S. B. Turnipseed and M. R. Madson, Rapid Commun. Mass Spectrom., 2012, 26, 2854-2864.

4 M. J. L. de Alda and D. Barcelo, Fresenius. J. Anal. Chem., 2001, 371, 437-447.

5 H. P. Jiang, Y. H. Zhang, X. G. Chen, J. Z. Lv and J. Zou, Anal. Methods, 2013, 5, 111-115.

6 S. A. M. Martin, P. Cash, S. Blaney and D. F. Houlihan, Fish Physiol. Biochem., 2001, 24, 259-270.

7 M. Carrera, B. Canas, C. Pineiro, J. Vazquez and J. M. Gallardo, J. Proteome Res., 2007, 6, 3070-3080.

8 G. Monti, L. De Napoli, P. Mainolfi, R. Barone, M. Guida, G. Marino and A. Amoresano, Anal. Chem., 2005, 77, 25872594.

9 H. F. Wu, A. D. Southam, A. Hines and M. R. Viant, Anal. Biochem., 2008, 372, 204-212.

10 A. Kullgren, F. Jutfelt, R. Fontanillas, K. Sundell, L. Samuelsson, K. Wiklander, P. Kling, W. Koppe, D. G. J. Larsson, B. T. Bjornsson and E. Jonsson, Comp. Biochem. Physiol., Part A: Mol. Integr. Physiol., 2013, 164, 44-53.

11 D. R. Ifa, C. Wu, Z. Ouyang and R. G. Cooks, Analyst, 2010, 135, 669-681.

12 H. Chen, G. Gamez and R. Zenobi, J. Am. Soc. Mass Spectrom., 2009, 20, 1947-1963.

13 M. E. Monge, G. A. Harris, P. Dwivedi and F. M. Fernández, Chem. Rev., 2013, 113, 2269-2308.

14 P. Nemes and A. Vertes, TrAC, Trends Anal. Chem., 2012, 34, 22-34.

15 J. M. Wiseman, D. R. Ifa, Y. Zhu, C. B. Kissinger, N. E. Manicke, P. T. Kissinger and R. G. Cooks, Proc. Natl. Acad. Sci. U. S. A., 2008, 105, 18120-18125.

16 Z. Pan, H. Gu, N. Talaty, H. Chen, N. Shanaiah, B. Hainline, R. Cooks and D. Raftery, Anal. Bioanal. Chem., 2007, 387, 539-549.

17 P. Nemes, A. S. Woods and A. Vertes, Anal. Chem., 2010, 82, 982-988.

18 B. Shrestha, P. Nemes, J. Nazarian, Y. Hathout, E. P. Hoffman and A. Vertes, Analyst, 2010, 135, 751-758.

19 M.-Z. Huang, H.-J. Hsu, J.-Y. Lee, J. Jeng and J. Shiea, J. Proteome Res., 2006, 5, 1107-1116.

20 M. S. Bereman, L. Nyadong, F. M. Fernandez and D. C. Muddiman, Rapid Commun. Mass Spectrom., 2006, 20, 3409-3411.

21 Y.-S. Shin, B. Drolet, R. Mayer, K. Dolence and F. Basile, Anal. Chem., 2007, 79, 3514-3518.

22 A. A. Stokes, D. J. Clarke, S. Weidt, P. Langridge-Smith and C. L. Mackay, Int. J. Mass Spectrom., 2010, 289, 54-57. 
23 H. Chen, S. Yang, M. Li, B. Hu, J. Li and J. Wang, Angew. Chem., Int. Ed., 2010, 122, 3117-3120.

24 P. Nemes and A. Vertes, Anal. Chem., 2007, 79, 8098-8106.

25 Y. Li, B. Shrestha and A. Vertes, Anal. Chem., 2006, 79, 523-532.

26 Y. H. Rezenom, J. Dong and K. K. Murray, Analyst, 2008, 133, 226-232.

27 J. S. Sampson, K. K. Murray and D. C. Muddiman, J. Am. Soc. Mass Spectrom., 2009, 20, 667-673.

28 I. X. Peng, R. R. O. Loo, E. Margalith, M. W. Little and J. A. Loo, Analyst, 2010, 135, 767-772.

29 G. Robichaud, J. Barry, K. Garrard and D. Muddiman, J. Am. Soc. Mass Spectrom., 2013, 24, 92-100.

30 B. Shrestha and A. Vertes, Anal. Chem., 2009, 81, 8265-8271.

31 P. Sripadi, J. Nazarian, Y. Hathout, E. Hoffman and A. Vertes, Metabolomics, 2009, 5, 263-276.

32 B. Shrestha, J. M. Patt and A. Vertes, Anal. Chem., 2011, 83, 2947-2955.
33 D. H. Evans, P. M. Piermarini and K. P. Choe, Phys. Rev., 2005, 85, 97-177.

34 M. A. Azevedo, L. R. Malabarba and J. R. Burns, Neotropical Ichthyology, 2010, 8, 87-96.

35 P. J. Bushmann, J. R. Burns and S. H. Weitzman, J. Morphol., 2002, 253, 187-195.

36 J. R. Burns and S. H. Weitzman, Copeia, 1996, 1996, 627-633.

37 R. Javonillo, J. R. Burns and S. H. Weitzman, in Reproductive Biology and Phylogeny of Fishes (Agnathans and Osteichthyes), Science Publishers, Enfield, NH, 2009, vol. 8A, ch. 17, pp. 721-761.

38 A. G. Ferrige, M. J. Seddon, S. Jarvis, S. John and A. Robert, Rapid Commun. Mass Spectrom., 1991, 5, 374-377.

39 Z. Zhang and A. G. Marshall, J. Am. Soc. Mass Spectrom., 1998, 9, 225-233.

40 L. Wan and R. B. van Huystee, J. Agric. Food Chem., 1993, 41, 896-898. 


\title{
Electronic Supplementary Information (ESI) for
}

\section{Comparative Local Analysis of Metabolites, Lipids and Proteins in Intact Fish Tissues by LAESI Mass Spectrometry}

\author{
Bindesh Shrestha, ${ }^{a}$ Robert Javonillo, ${ }^{b, c}$ John R. Burns, ${ }^{b}$ Zsolt Pirger, ${ }^{\text {d }}$ and Akos Vertes ${ }^{* a}$ \\ ${ }^{a}$ Department of Chemistry, W. M. Keck Institute for Proteomics Technology and Applications, The George Washington \\ University, Washington, DC, 20052, USA \\ ${ }^{b}$ Department of Biological Sciences, The George Washington University, Washington, DC, 20052, USA \\ ${ }^{c}$ Current address: Department of Natural Sciences, Coppin State University, Baltimore, MD, 21216, USA \\ ${ }^{d}$ Department of Chemical-Ecology and Zoology, Centre for Ecological Research, Hungarian Academy of Sciences, Balaton \\ Limnological Institute, Tihany, Hungary \\ *Corresponding author. E-mail: vertes@gwu.edu. Phone: +1 (202) 994-2717. Fax: +1 (202) 994-5873.
}

Table S1. Tentative assignments of metabolite and lipid ions observed in the gill glands of mature $A$. anisitsi. Lipid assignments included phosphatidylcholine (PC), phosphatidylserine (PS), phosphatidylinositol (PI), phosphatidylethanolamine $\quad(\mathrm{PE})$ sphingomyelin $\quad(\mathrm{SM})$ and phosphatidylglycerol (PG) species.

\begin{tabular}{|c|c|c|c|}
\hline Metabolite and Lipid Ions ${ }^{a}$ & $m / z_{\text {calc. }}{ }^{b}$ & $m / z_{\text {meas. }}$ & $\Delta m / z$ \\
\hline choline $+\mathrm{NH}_{4}^{+}$ & 104.118 & 104.122 & 0.004 \\
\hline creatine $+\mathrm{Na}^{+}$ & 131.081 & 131.058 & 0.023 \\
\hline acetylcholine $+\mathrm{H}^{+}$ & 146.165 & 146.167 & 0.002 \\
\hline histidine $+\mathrm{NH}_{4}^{+}$ & 155.092 & 155.068 & 0.024 \\
\hline- & - & 131.058 & - \\
\hline lysine $+\mathrm{H}^{+}$ & 146.165 & 146.167 & 0.002 \\
\hline- & - & 149.060 & - \\
\hline- & - & 165.052 & - \\
\hline- & - & 118.994 & - \\
\hline tryptophan $+\mathrm{Na}^{+}$ & 204.172 & 204.147 & 0.025 \\
\hline- & - & 117.026 & - \\
\hline- & - & 163.987 & - \\
\hline hexose $+\mathrm{Na}^{+}$ & 180.097 & 180.050 & 0.047 \\
\hline acetylgalactosamine $+\mathrm{H}^{+}$ & 221.128 & 221.135 & 0.007 \\
\hline thiamine $(\mathrm{B} 1)+\mathrm{Na}^{+}$ & 300.998 & 300.961 & 0.037 \\
\hline- & - & 219.079 & - \\
\hline coenzyme-A $(\mathrm{CoA})+\mathrm{H}^{+}$ & 767.594 & 767.603 & 0.009 \\
\hline cholesterol $+\mathrm{Na}^{+}$ & 369.349 & 369.356 & 0.007 \\
\hline dehydroepiandrosterone $+\mathrm{H}^{+}$ & 288.424 & 288.379 & 0.045 \\
\hline- & - & 286.124 & - \\
\hline dehydrotestosterone $+\mathrm{H}^{+}$ & 290.442 & 290.522 & 0.080 \\
\hline- & - & 289.665 & - \\
\hline- & - & 300.115 & - \\
\hline 11-ketotestosterone $+\mathrm{H}^{+}$ & 302.407 & 302.397 & 0.010 \\
\hline 5-androstenetriol $+\mathrm{H}^{+}$ & 307.226 & 307.254 & 0.028 \\
\hline- & - & 353.141 & - \\
\hline- & - & 362.195 & - \\
\hline
\end{tabular}




\begin{tabular}{|c|c|c|c|}
\hline $\mathrm{PC}[32: 0]+\mathrm{K}^{+}$ & 758.546 & 758.550 & 0.004 \\
\hline $\mathrm{PC}[34: 4]+\mathrm{Na}^{+}$ & 760.525 & 760.575 & 0.050 \\
\hline $\mathrm{PC}[36: 5]+\mathrm{H}^{+}$ & 780.553 & 780.556 & 0.003 \\
\hline $\mathrm{PC}[34: 1]+\mathrm{K}^{+}$ & 782.546 & 782.560 & 0.014 \\
\hline $\mathrm{PC}[38: 8]+\mathrm{H}^{+}$ & 802.538 & 802.534 & 0.004 \\
\hline $\mathrm{PC}[36: 3]+\mathrm{Na}^{+}$ & 806.546 & 806.578 & 0.032 \\
\hline $\mathrm{PC}[40: 10]+\mathrm{H}^{+}$ & 826.538 & 826.548 & 0.010 \\
\hline $\mathrm{PC}[40: 9]+\mathrm{H}^{+}$ & 828.553 & 828.546 & 0.007 \\
\hline $\mathrm{PC}[40: 5]+\mathrm{H}^{+}$ & 836.616 & 836.614 & 0.002 \\
\hline $\mathrm{PC}[38: 6]+\mathrm{K}^{+}$ & 844.525 & 844.529 & 0.004 \\
\hline $\mathrm{PC}[42: 11]+\mathrm{H}^{+}$ & 852.553 & 852.567 & 0.014 \\
\hline $\operatorname{PS}[38: 2]+\mathrm{K}^{+}$ & 854.530 & 854.564 & 0.037 \\
\hline $\operatorname{PS}[38: 1]+\mathrm{K}^{+}$ & 856.546 & 856.585 & 0.039 \\
\hline $\mathrm{PI}[35: 2]+\mathrm{H}^{+}$ & 833.553 & 833.577 & 0.024 \\
\hline $\mathrm{PI}[33: 1]+\mathrm{Na}^{+}$ & 845.517 & 845.522 & 0.005 \\
\hline $\mathrm{PI}[35: 1]+\mathrm{Na}^{+}$ & 857.551 & 857.596 & 0.045 \\
\hline $\mathrm{PI}[40: 1]+\mathrm{Na}^{+}$ & 929.645 & 929.622 & 0.023 \\
\hline $\mathrm{PE}[32: 1]+\mathrm{H}^{+}$ & 732.553 & 732.546 & 0.007 \\
\hline $\mathrm{PE}[40: 6]+\mathrm{H}^{+}$ & 808.548 & 808.582 & 0.034 \\
\hline $\mathrm{PE}[41: 4]+\mathrm{H}^{+}$ & 810.600 & 810.611 & 0.011 \\
\hline $\mathrm{PE}[41: 5]+\mathrm{Na}^{+}$ & 830.530 & 830.567 & 0.037 \\
\hline $\mathrm{PE}[42: 11]+\mathrm{Na}^{+}$ & 832.525 & 832.570 & 0.045 \\
\hline $\mathrm{PE}[40: 4]+\mathrm{K}^{+}$ & 834.541 & 834.496 & 0.047 \\
\hline $\mathrm{PE}[41: 2]+\mathrm{Na}^{+}$ & 836.614 & 836.593 & 0.021 \\
\hline $\mathrm{PE}[40: 6]+\mathrm{K}^{+}$ & 846.504 & 846.506 & 0.002 \\
\hline $\mathrm{SM}[34: 1]+\mathrm{Na}^{+}$ & 725.556 & 725.561 & 0.005 \\
\hline $\mathrm{SM}[38: 1]+\mathrm{H}^{+}$ & 835.589 & 835.605 & 0.016 \\
\hline $\mathrm{SM}[41: 2]+\mathrm{K}^{+}$ & 837.624 & 837.645 & 0.021 \\
\hline $\mathrm{PG}[37: 1]+\mathrm{K}^{+}$ & 829.535 & 829.561 & 0.026 \\
\hline $\mathrm{PG}[40: 6]+\mathrm{Na}^{+}$ & 831.551 & 831.584 & 0.033 \\
\hline $\mathrm{PG}[40: 4]+\mathrm{Na}^{+}$ & 835.584 & 835.605 & 0.021 \\
\hline
\end{tabular}

${ }^{a}$ PC, PS, PI, PE, SM, and PG species are identified by the total length of the acyl chain(s) and the number of double bonds in parentheses.

${ }^{b}$ The monoisotopic masses were calculated using the NIST Isotope Calculator package (ISOFORM, Version 1.02), and the measured $\mathrm{m} / \mathrm{z}$ values were obtained from typical mass spectra. 